\title{
OVIPOSITION BEHAVIOR AND WATER CHANGES IN THE OÖTHECAE OF LOPHOBLATTA BREVIS (BLATTARIA: BLATTELLIDAE: PLECTOPTERINAE)**
}

\author{
By Louis M. Roth
}

Pioneering Research Laboratory, U. S. Army Natick Laboratories, Natick, Massachusetts or 760

Oviposition behavior and changes in the water content of cockroach oöthecae during development of the eggs has been related to the evolution of ovoviviparity and viviparity in the Blattaria (Roth and Willis, 1955a, 1958; Roth, 1967a, 1967b). Based on the shape of water uptake curves, I suggested (1967a) that ovoviviparous cockroaches (Blaberidae) may have evolved from blattellid-like ancestors whose oöthecae I) had low water contents $(<50 \%)$ initially, 2) were carried externally until the eggs hatched, and 3) had S-shaped water uptake curves during embryogenesis. This stage in the evolution of ovoviviparity was indicated with a query (Roth, 1967a, Fig. I4) because no species was known to fit the category. At that time, the only forms known that carried their eggs externally for the entire embryogenetic period were species of Blattella, Chorisia fulvotestacea Princis, and a third questionably identified genus (Roth, I967b); these are members of Blattellinae, genera of Blattellidae which rotate their oothecae $90^{\circ}$ after they are formed. The oöthecae of Blattella and Chorisia initially have a high water content (usually $>56 \%$ ), and do not have an S-shaped water uptake curve; I suggested that they could be placed more logically in the pathway for the evolution of viviparity than for that of ovoviviparity.

Among the cockroaches I collected in the Amazon (see acknowledgements) was a female of Lophoblatta brevis Rehn. It was taken on a banana plant in the town of Moura, on the Rio Negro, July 2 I, 1967. The female was carrying an oötheca with the keel upright and the eggs hatched the day after the specimen was collected. The oötheca of Lophoblatta is not rotated and this plus other characters places this genus in the Plectopterinae of McKittrick (1964); it is the first plectopterine genus known which carries its oötheca until the eggs hatch.

The oötheca of $L$. brevis is relatively thin, contains very few crystals of calcium oxalate, and the serrations of the keel are greatly reduced (Fig. 3). The egg case has an unusual shape, being wider

*Manuscript received by the editor March 20, 1968 

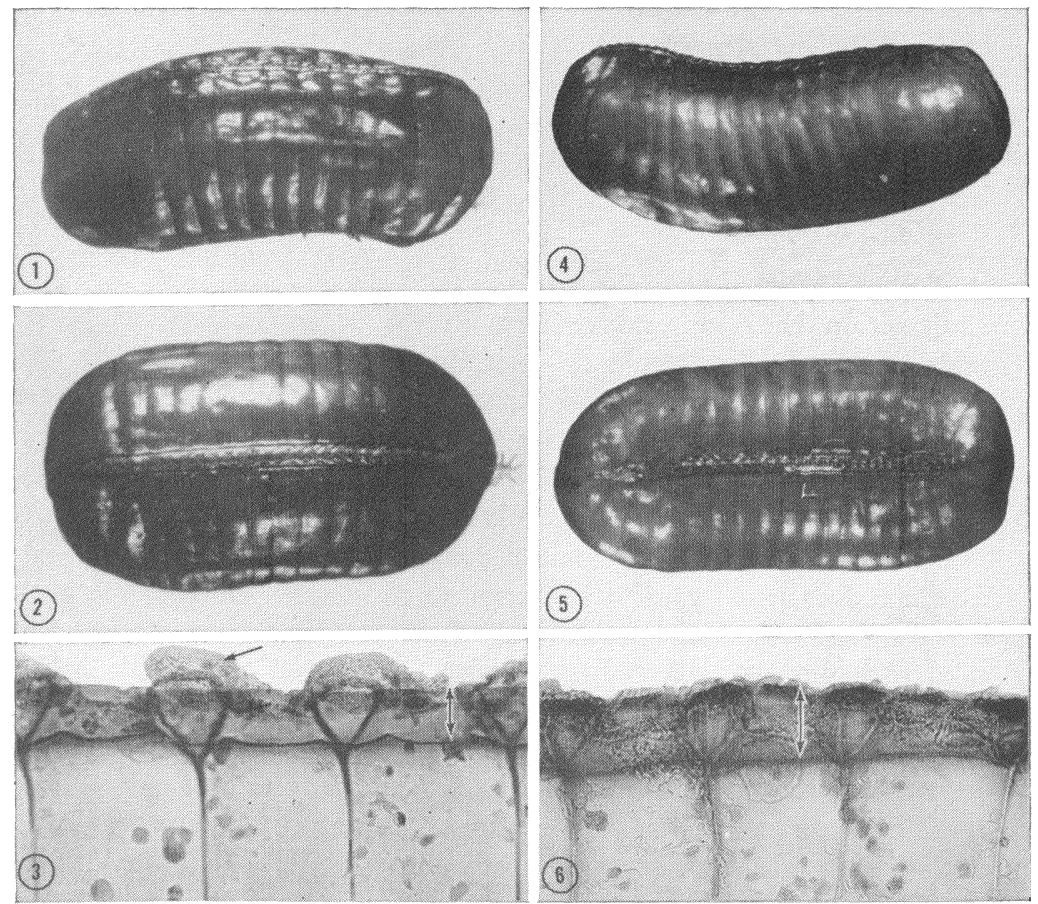

Figs. 1-6. Oöthecae of Lophoblatta spp. Figs. 1-3. L. brevis. Fig. 1. Lateral view $(X 12)$. Fig. 2. Dorsal view $(X 11.5)$. Fig. 3. Portion of keel region $(X$ 67.6). Figs. 4-6. L. arlei. Fig. 4. Lateral view (X 9.4). Fig. 5. Dorsal view $(X 9.4)$. Fig. 6. Portion of keel region $(X 67.6)$.

The keel region (Figs. 3 and 6 ) is an inner view of one half of the oöthecal wall, cleared in xylene and mounted in Permount. In Fig. 3, the protruberances (arrow) are spongy-like bodies, normally found above each egg; in Fig. 6, these bodies were removed to show the actual margin of the keel. The main part of the keel (double-headed arrows) lies flat against the eggs and only the small reduced serrations protrude upwards.

than high, and somewhat flattened dorsally and ventrally (Figs. I, 2). It does not appear to increase in size or change shape as the eggs develop. The end of the oötheca in the vestibulum of the female is lighter in color than the remainder of the egg case and apparently is permeable to water. Except for its unique shape, the oötheca of $L$. brevis resembles that of some species of Blattella. Other species of Lophoblatta have thick, hard oöthecae that are deposited shortly after their formation (Roth, I968a: Lophoblatta sp. $A=$ Lophoblatta fissa Saussure and Zehntner, Fig. 76; and Lophoblatta 
sp. B, Fig. 78). Perhaps, a closer study of Lophoblatta may reveal sufficient differences in species like $L$. brevis to warrant placing them (or the others) in different genera.

The dorso-ventral flattening of the oötheca of $L$. brevis and $L$. arlei (see below) may have adaptive significance in that it would allow the female to rest or crawl into more narrow spaces and reduce the chances of losing the oöthecae prematurely, than if the egg cases were of the usual shape (i.e., taller than wide) and carried with the long axes of the eggs in the vertical position. Females of Blattella germanica (L.) that carry the oötheca in a horizontal position could crawl into a space which averaged 0.4 of a $\mathrm{mm}$. narrower than females that were still carrying the egg case perpendicularly (i.e., before rotation) (Wille, I920). The adaptive value of rotation in the Blattellinae may well be to allow the female to crawl into narrow crevices while carrying its oötheca, and also to reduce the chances of the egg case being knocked off accidentally while crawling in these narrow spaces. In the ovoviviparous Blaberidae, rotation of the oötheca reorients the eggs so that their long axes lay in the plane of the cockroach's width and would thus allow for growth of the eggs by stretching the uterus, principally in a lateral direction, in insects that are usually quite flat (Roth, 1967b). The significance of rotation of the oötheca in the oviparous Blattellidae differs from its importance in the ovoviviparous and viviparous Blaberidae, but its occurrence in oviparous forms preadapted them for the evolution of species which incubated their eggs internally.

A colony of $L$. brevis was established from the female collected in Moura, and from another female in Puraquequera, Rio Negro, July 31, 1967. Water determinations were made on oöthecae of different ages (removed from females at various times after oviposition). The results are shown in Fig. 7. The initial water content of the oötheca is about $36 \%$. Little change in this percentage takes place until about the ninth day. A marked increase in water content occurs between days 9 and II, followed by a more gradual rise in percentage of water until just before the eggs hatch, at which time it reaches about $75 \%$. The water uptake curve is S-shaped as was predicted (Roth, 1967a) and compares well with other plectopterines that drop their oöthecae after forming them and which have $<50 \%$ water at the time of oviposition (see Roth, I967a, Fig. 3). The shape of the water uptake curve also is very similar to that of the ovoviviparous cockroach Nauphoeta cinerea (Olivier) (see Roth, 1967a, Fig. 8).

The oötheca of $L$. brevis is carried for 31 to 34 days (Figs. 9, ro) and after the eggs hatch a new eggcase is formed 9 to Io days later. 


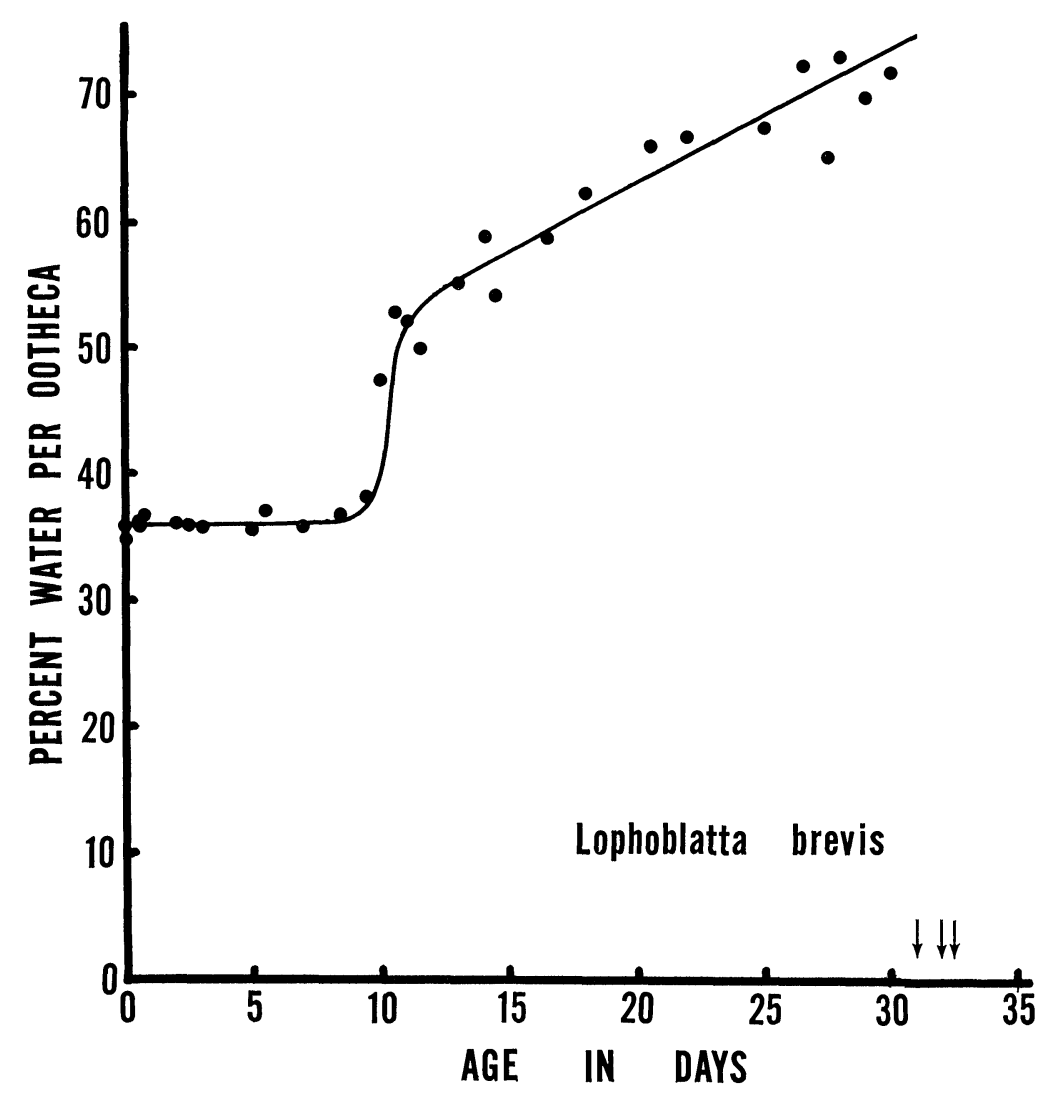

Fig. 7. Changes in water content, with age, in the oöthecae of Lophoblatta brevis. Arrows indicate days when eggs hatched.

The first adults appeared in the culture in 84 to 85 days after the eggs hatched. After the first oötheca, oviposition occurs about every 40 to 44 days. If the oötheca is removed manually from the female prematurely, a new oötheca is formed much earlier than it would be if the eggs were allowed to remain attached to the female until hatching. The younger the age of the oötheca when detached from the female, the longer it takes to form a new egg case (Fig. 8). Recently formed oöthecae that are removed from the female lose water rapidly and the egg case collapses. These results are similar to those obtained with Blattella germanica (L.) and Blattella vaga (Roth and Stay, 1962) and show that the presence of an oötheca in 
the vestibulum of the female inhibits the development of the ovaries. The inverse relationship between time of removal of the oötheca and time required to ovulate again can be explained by the fact that the basal oöcytes in females carrying eggs near hatching time are larger than those in females that have recently oviposited and, therefore, less time is required for the oöcytes to mature once the inhibiting influence of the oötheca is removed (Roth and Stay, 1962).

At the time of ovulation, the ovariole of $L$. brevis contains only one oöcyte in Zone $\mathrm{V}$, and there are only 6 oöcytes in Zone IV. Thus, the ovarioles resemble those of oviparous Blattella and Chorisia and certain Blaberidae (Roth, 1968b).

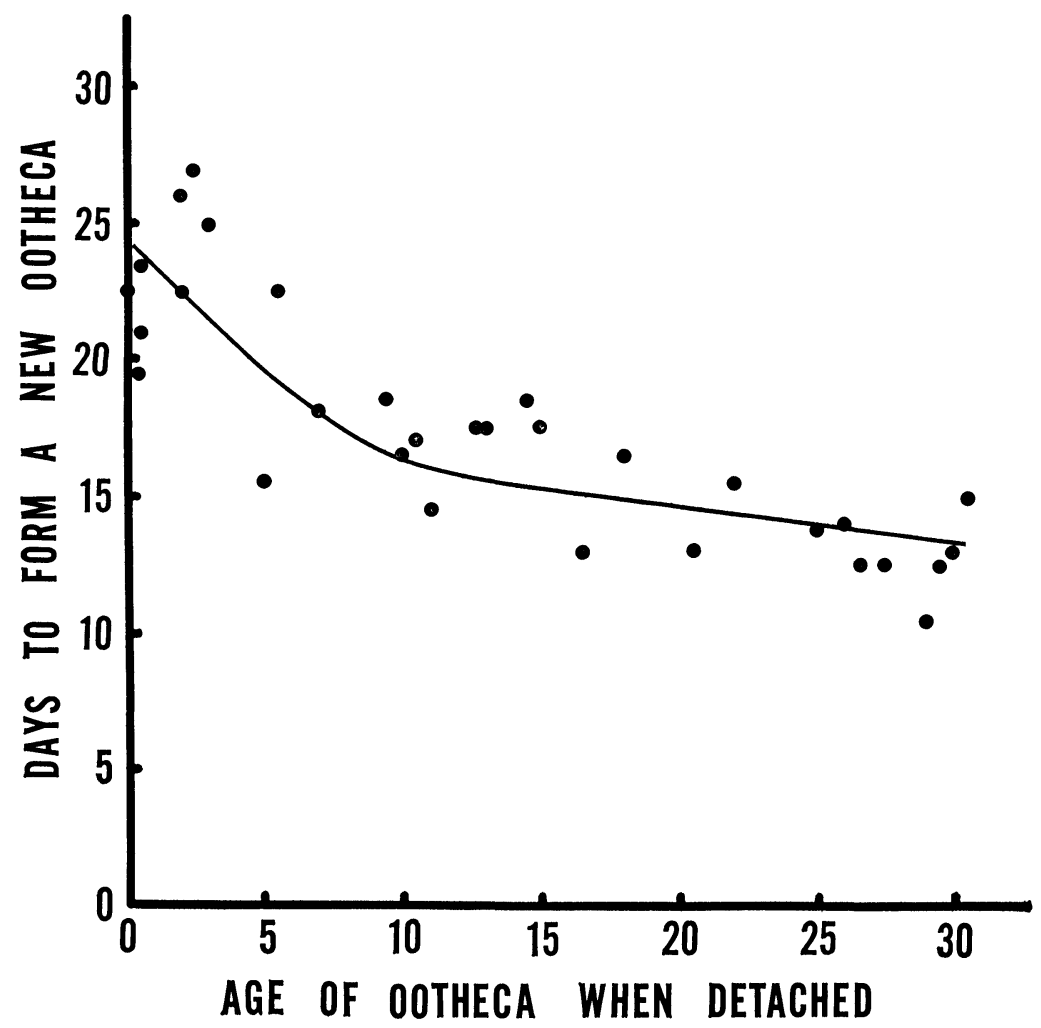

Fig. 8. Relationship between age (days) of the oöthecae when removed from the female and the time required by Lophoblatta brevis to ovulate again. 
The structure of the oötheca and ovaries, as well as oviposition behavior of Lophoblatta brevis indicate that, with the exception of rotation of the oötheca, reproduction in the Plectopterinae has evolved along the same general pathway as that which occurred in the Blattellinae. However, at the time of oviposition, most plectopterine oöthecae have $<50 \%$ water, whereas the Blattellinae have $>50 \%$ water. Although the water uptake curve of the plectopterine L. brevis can be used as an example to link the oviparous Blattellidae with the ovoviviparous Blaberidae, it is likely that ovoviviparity arose from a Blattellinae-like form because rotation of the oötheca was a preadaptation necessary for the evolution of the Blaberidae (Roth, I967b). Because the initial water content of the oöthecae of practically all Blattellinae examined have been found to be more than $50 \%$, I suggested that viviparity (in the only viviparous species known, Diploptera punctata (Esch.) the eggs initially contain about $65 \%$ water) arose from a blattelline stock and Blattella spp. was an important link between oviparous and viviparous forms (Roth,

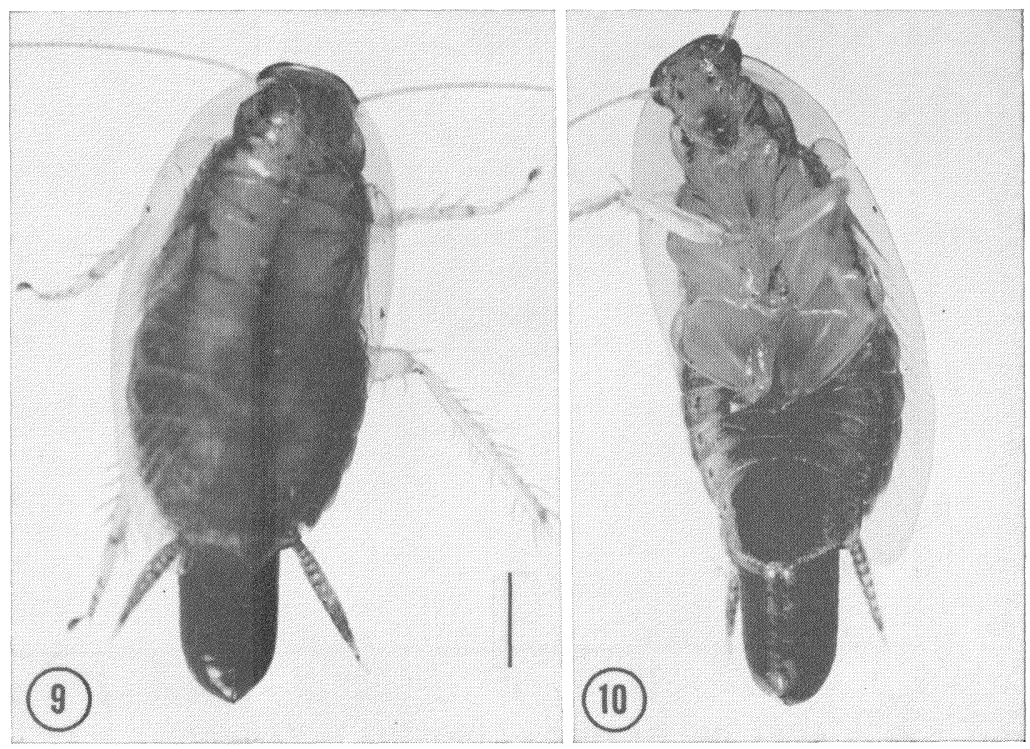

Figs. 9-10. Dorsal and ventral views of a female of Lophoblatta brevis, carrying an oötheca (line $=2 \mathrm{~mm}$.). 
I967a). However, it is probable that there are Blattellinae whose oöthecae contain $<50 \%$ water initially, which are carried attached externally by the female for the entire embryogenetic period, and which have an S-shaped water uptake curve. Such blattellines when eventually found will add additional support to the hypothesis that ovoviviparity also arose from a blattellinae-like stock.

Lophoblatta arlei (R. S. - Albuquerque), a closely related but much larger species than $L$. brevis, was collected in an oriole nest near Serra Tamendaui, Rio Negro, July I8-I9, I967. Its oötheca is similar but larger (Figs. 4-6) than that of L. brevis, and it too is carried externally for the entire embryogenetic period. The water content of the oötheca when first formed is $38.6 \pm 0.0(\mathrm{~N}=2)$. Calcium oxalate crystals appear to be absent, or if present, are very sparse in the wall of the oötheca. There is only I oöcyte in Zone V, and 5 in Zone IV of the ovariole. Unfortunately, I could not establish a culture of this species, but, undoubtedly, water uptake is similar to that of $L$. brevis.

\section{SUMMARY}

The blattellids Lophoblatta brevis, and $L$. arlei are the first members of the Plectopterinae found that carry their oöthecae externally until the eggs hatch. Except for the absence of rotation of the oötheca, their oviposition behavior is similar to Blattella and Chorisia, both genera of Blattellinae.

The structure of the ovaries and oötheca, as well as the oviposition behavior of $L$. brevis and $L$. arlei show that, except for not rotating the oötheca, reproductive evolution in the Plectopterinae has followed the same general pathway as that undergone in the Blattellinae.

The water uptake curve of the eggs in the oötheca of $L$. brevis is sigmoid-shaped and typical of species that have a low water content $(<50 \%)$ at the beginning of embryogenesis. This is the first demonstration in the Blattellidae that the curve for water uptake by eggs in an externally carried oötheca can be S-shaped and similar to ovoviviparous species that incubate their eggs internally.

Because rotation of the oötheca was a necessary prerequisite for the evolution of ovoviviparity in the Blaberidae, Blattellinae-like species were probably the forerunners of this family. However, though they likely exist, no Blattellinae are known whose oöthecae initially have low water contents, are carried by the mother during embryogenesis, and whose eggs have an S-shaped water uptake curve. 


\section{ACKNOWLEDGEMENTS}

I thank Dr. Ashley Gurney for determining the species. The specimens were collected in Brazil during Phase $\mathrm{C}$ of the Alpha Helix Expedition to the Amazon in 1967. I am grateful to the National Science Foundation for support on the Amazon Expedition under grant NSF-GB-59r6.

\section{McKittrick, F. A.}

\section{References Cited}

1964. Evolutionary studies of cockroaches. Cornell Univer. Agric. Exp. Sta. Mem. 389, 197 pp.

Roth, L. M.

1967a. Water changes in cockroach oöthecae in relation to the evolution of ovoviviparity and viviparity. Ann. Entom. Soc. Amer. 60: 928-946.

$1967 \mathrm{~b}$. The evolutionary significance of rotation of the oötheca in the Blattaria. Psyche 74: 85-103.

1968a. Oöthecae of the Blattaria. Ann. Entom. Soc. Amer. 61: 83-111.

1968b. Ovarioles of the Blattaria. Ann. Entom. Soc. Amer. 61: 132-140.

Roth, L. M. and B. Stay

1962. Oöcyte development in Blattella germanica and Blattelia vaga (Blattaria). Ann. Entom. Amer. 55: 633-642.

Roth, L. M. and E. R. Willis

1955a. The water content of cockroach eggs during embryogenesis in relation to oviposition behavior. Jour. Exp. Zool. 128: 489-509.

1958. An analysis of oviparity and viviparity in the Blattaria. Trans.

WILLE, J. Amer. Entom. Soc. 83: 221-238.

1920. Biologie und Bekämpfung der deutschen Schabe (Phyllodromia germanica L.). Monogr. Angew. Ent. Nr. 5, Zeit. Angew. Ent. Beiheft 1, Band 7, $140 \mathrm{pp}$. 

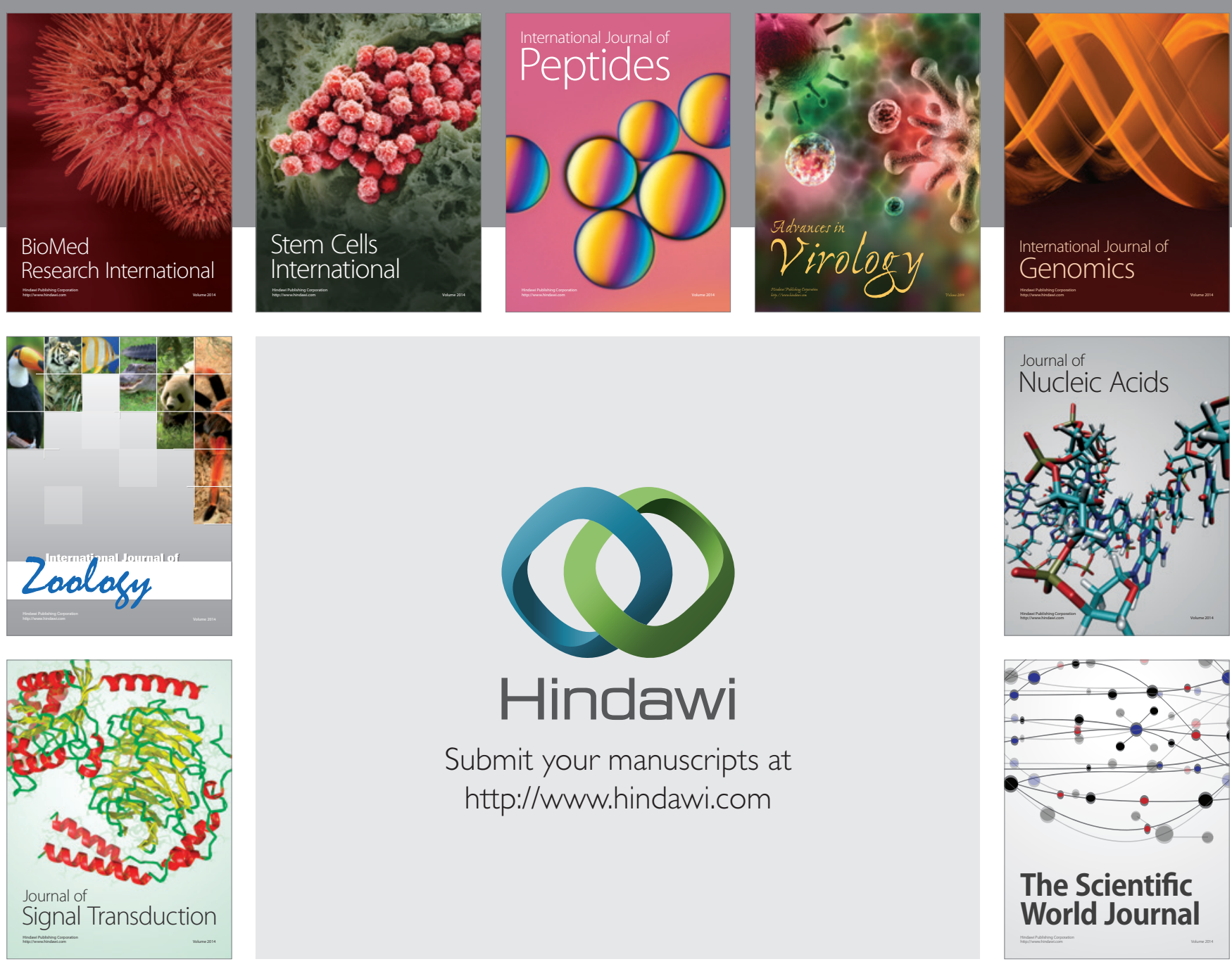

Submit your manuscripts at

http://www.hindawi.com
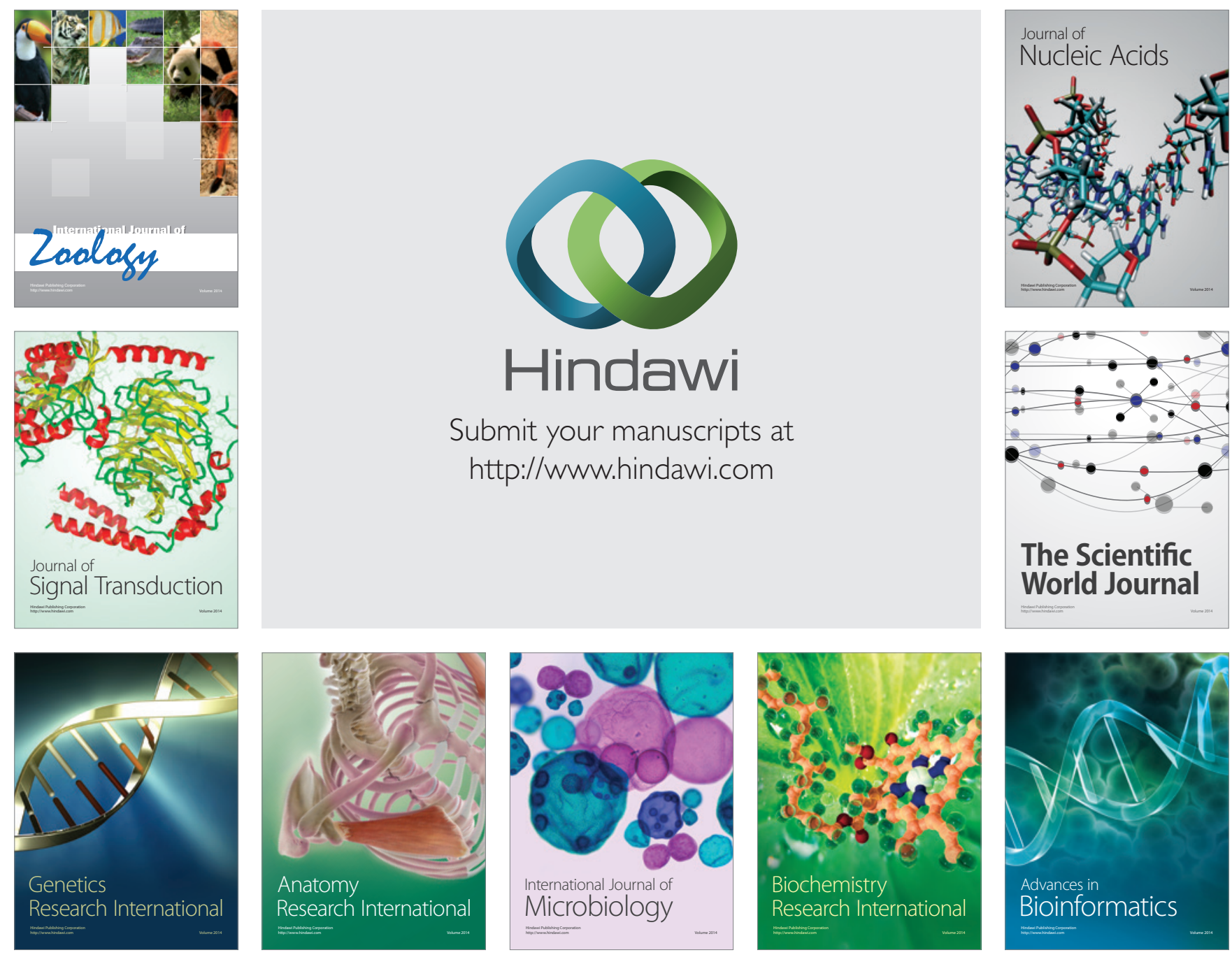

The Scientific World Journal
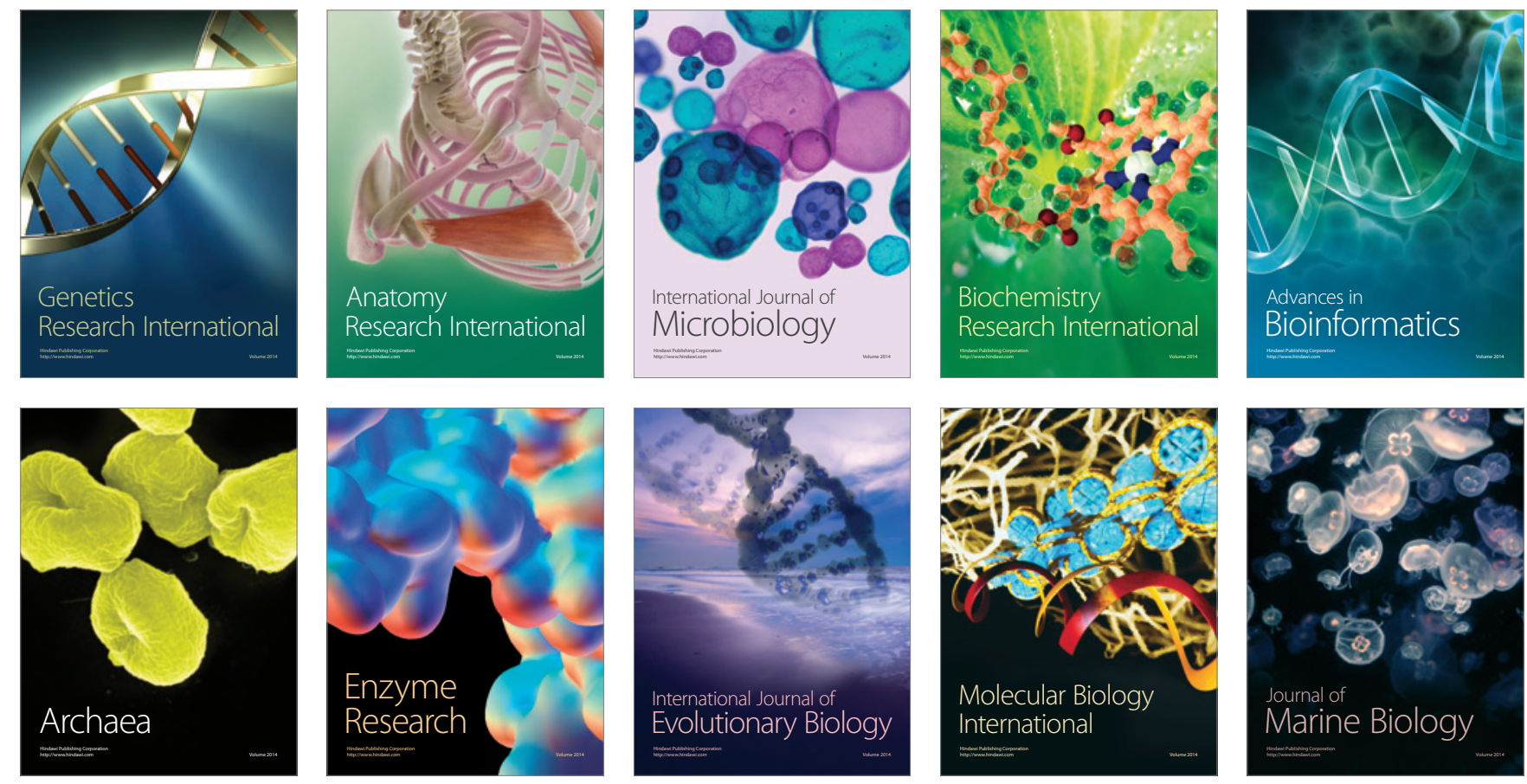